\title{
Six Cases of Fungal Peritonitis Complicating Peritoneal Dialysis in a Single Center in Sudan
}

\author{
Elwaleed A M Elhassan ${ }^{a^{*},}$ Maha A Hummeida ${ }^{a}$, Osman-mahir M A Mahira ${ }^{a}$ Hisham M Alia, Aymun I \\ Mobarak $^{\mathrm{a}}$, Jamal Abdel-Raheem ${ }^{\mathrm{a}}$, Um-Alhasan Mohamed ${ }^{\mathrm{a}}$, Hassan A Musa ${ }^{\mathrm{b}}$ and Hasan Abu-Aisha ${ }^{\mathrm{a}}$ \\ a. Ribat center for Regular Peritoneal Dialysis, Ribat University Hospital. \\ b. Department of Microbiology, Ribat University Hospital, Burri, Khartoum, Sudan
}

\begin{abstract}
Introduction: A national program of continuous ambulatory peritoneal dialysis (CAPD) has only recently been established in Sudan. In the head center of this national program, six of the 67 peritonitis episodes that were diagnosed during its 30 months of function were fungal in origin ( $9 \%$ of all episodes, 0.12 episode per year at risk). Here we describe the clinical features, predisposing factors, and outcomes of these six cases.
\end{abstract}

Case series: Clinical presentation of fungal peritonitis did not differ from other cases of peritonitis. Among the six cases that were diagnosed in our center, five cases were due to Candida species and only one was due to Aspergillus. All patients had received antibiotic therapy within one month of diagnosing fungal peritonitis; five of them had received intraperitoneal (IP) antibiotics for a previous episode of bacterial peritonitis and one patient had received a course of oral antibiotics for exit site infection. Two of the patients were diabetic. All patients were treated with oral fluconazole, $200 \mathrm{mg}$ daily, for three weeks, and all had their dialysis catheter removed. One patient died, and the others were transferred permanently to hemodialysis (HD). Two patients developed encysted intra-abdominal fluid collections 15 and 48 days after catheter removal.

Conclusion: Fugal peritonitis complicating CAPD is not uncommon in our center, which serves a major portion of the CAPD population in the Sudan. Most patients responded to oral fluconazole treatment and catheter removal, but two of them suffered from late complications.

\footnotetext{
* Corresponding author; Ribat Center for Regular Peritoneal Dialysis, Burri, P.O. Box 55, Khartoum, Sudan.

Email: waleedali@yahoo.com
}

Keywords: fungal peritonitis, peritoneal dialysis, Sudan

\section{Introduction}

Since continuous ambulatory peritoneal dialysis (CAPD) was introduced as a treatment modality for patients with end stage renal disease (ESRD), peritonitis has been one of the most important complications that can lead to technique failure. Fungal peritonitis is a rare but serious complication of CAPD, being responsible for 2.6-14.3\% of all peritonitis episodes occurring in this set of patients [1-9]. Given the high complication rate that may result in mortality and technique failure, fungal peritonitis is considered to have a particularly poor prognosis [8-10].

There is no difference between the clinical presentation of bacterial and fungal peritonitis, although in fungal peritonitis the symptoms are usually milder and may be disregarded by the patient for several weeks before coming to hospital. Candida species constitute the most common isolate, accounting for $70-89 \%$ of cases [5-8].

Predisposition to fungal infections is multi-factorial; possible predisposing factors include diabetes mellitus, use of immunosuppressive drugs, a break in sterile technique and extensive use of antibiotics for bacterial peritonitis. Prior use of antibiotics have been found to contribute the most to fungal overgrowth $[8,11]$, but this is not always the case [7].

Treatment of fungal peritonitis is often difficult, and immediate catheter removal in addition to systemic antifungal therapy is recommended by the international society of peritoneal dialysis (ISPD) [12].

CAPD has been introduced in Sudan in June 2005 as a national program [13]. Ribat PD center is the head center of the program and serves a major portion of CAPD patients enrolled up to date $(82 / 196)$. 
During the 30 months of this center activity, 6 of 67 peritonitis episodes were fungal in origin $(9 \%)$. This is a rather high percentage compared to that reported from other centers in recent years [6-9]. Here we describe the clinical features, predisposing factors, and outcomes of those episodes.

\section{Case Series}

Between June 2005 and December 2007, 82 patients with ESRD underwent regular PD in our center; all of them were on CAPD. Peritoneal dialysis access was achieved with a Tenckhoff catheter; most catheters were inserted by open surgical dissection and a few were inserted by means of the modified Seldinger technique.

During this period, 67 episodes of peritonitis were recorded; six of them were fungal in origin $(9 \%)$. The six episodes occurred in six different patients; four males and two females, with a mean age of 57.2 years (range $42-67$ years). Their mean duration on CAPD was 10.8 months (range 2.3 - 21.4 months). Two of them were diabetic. All patients had received antibiotics within one month of fungal peritonitis: Five patients had received intraperitoneal (IP) antibiotics for bacterial peritonitis and one patient had received oral antibiotics for exit site infection.

All patients presented with abdominal pain and cloudy effluent, three of them had fever, one had diarrhea and one had vomiting. The dialysate white cell count varied between $200-1905 / \mathrm{mm}^{3}$, with neutrophil predominance in all cases.

Gram stain of the deposit yielded the diagnosis in the majority of cases. Culture was performed from the dialysate deposit on solid culture media (MacConkey, blood agar and chocolate agar) incubated for 72 hours at $37^{\circ} \mathrm{C}$. The interval between presentation and diagnosis of fungal peritonitis varied between $2-24$ days; five cases were due to Candida species and only one case was due to Aspergillus; further identification of Candida subtypes was not feasible.

Upon diagnosis of fungal peritonitis, all patients were treated with oral fluconazole $200 \mathrm{mg}$ once daily for three weeks, since no fluconazole preparation for intravenous or intraperitoneal use was available at the time. The catheter was removed in all patients, but no culture was done for its tip after its removal.The mean interval between the diagnosis of fungal peritonitis and catheter removal was 2.7 days (range 1-6 days).

One of the two diabetic patients died from sepsis three days after catheter removal; in her case the catheter had been removed within 24 hours from diagnosis.
The other diabetic patient also had his catheter removed within 24 hours of diagnosis and was shifted to HD. He showed prompt clinical improvement but he presented again after two weeks with an abscess in the old tunnel tract that required surgical drainage, and an encysted fluid collection in the anterior abdominal wall that was aspirated under ultra-sound guidance. The encysted fluid did not re-accumulate and the patient has been doing well on HD since then.

Another patient had her catheter removed four days after the diagnosis of fungal peritonitis and was shifted to HD. She showed good initial response to treatment but presented again after 48 days with an encysted intraabdominal fluid collection that was aspirated under ultrasound guidance.

The fourth patient with Candida peritonitis had concomitant Staphylococcus epidermidis peritonitis which was sensitive to cefazolin. He responded well to a combination of antifungal and antibacterial treatment with no complications, and was shifted permanently to HD.

The fifth and sixth patients responded well to treatment and had no immediate or long term complications in spite of the catheter being removed after 6 days of the diagnosis in one of them; both were transferred permanently to HD.

\section{Discussion}

The proportion of CAPD related peritonitis due to fungi is currently $9 \%$ in our center, which is comparable to that reported in the literature $(2.6-14.3 \%)$ [1-9]; however, the proportions reported from most centers in more recent years are lower than ours [6-9]. The causative organism was Candida species in 5 of 6 patients $(83.3 \%)$, in agreement with data from the literature $(70-89.3 \%)$ [1-9].

All our patients had received antibiotics within one month of fungal peritonitis; five received intraperitoneal antibiotics for bacterial peritonitis and one received systemic antibiotics for exit site infection. Another predisposing factor was diabetes mellitus in two of the patients. Intraperitoneal or systemic antibiotics were hence the major predisposing factor for fungal peritonitis in our patients.

Several suggestions proposing to reduce the incidence of fungal peritonitis were raised. Avramovic et al attributed their low incidence of fungal peritonitis $(2.6 \%)$ to the inhospital treatment of bacterial peritonitis episodes [14]. Prophylactic use of oral nystatin or fluconazole during antibiotic therapy has also been suggested to play a role in preventing fungal peritonitis [15]. 
None of our patients resumed peritoneal dialysis. Brian et al [16] suggested that removal of the dialysis catheter and treatment with fluconazole may provoke the formation of massive peritoneal adhesions and recurrent peritoneal abscesses, as has happened to two of our patients. They believe that temporary discontinuation of peritoneal dialysis is neither essential nor desirable in the management of fungal peritonitis, and they suggest that peritoneal lavage with a temporary catheter and administration of intraperitoneal and oral antifungal agents offer an effective alternative regimen for the management of fungal peritonitis in CAPD patients. This approach, however, has not been verified so far.

\section{Conclusion}

Fugal peritonitis complicating CAPD is not uncommon in our center, which serves a major part of the CAPD population in the Sudan. Most of our infected patients responded to oral fluconazole treatment and catheter removal, but two of them suffered from late complications.

\section{References}

1. Goldie SJ, Kiernan-Tridle L, Torres C, Gorban-Brennan N, Dunne D, Kliger AS, Finkelstein FO. Fungal peritonitis in a large chronic peritoneal dialysis population: a report of 55 episodes. Am J Kidney Dis. 1996;28:86-91.

2. Chan TM, Chan CY, Cheng SW, Lo WK, Lo CY, Cheng IK. Treatment of fungal peritonitis complicating continuous ambulatory peritoneal dialysis with oral fluconazole: a series of 21 patients. Nephrol Dial Transplant. 1994;9:539-42.

3. Zelenitsky S, Barns L, Findlay I, Alfa M, Ariano R, Fine A, Harding G. Analysis of microbiological trends in peritoneal dialysis-related peritonitis from 1991 to 1998 . Am J Kidney Dis. 2000;36:1009-13.

4. Prasad KN, Prasad N, Gupta A, Sharma RK, Verma AK, Ayyagari A. Fungal peritonitis in patients on continuous ambulatory peritoneal dialysis: a single Indian center experience. J Infect. 2004;48:96-101.

5. Manzano-Gayosso $\mathrm{P}$, Hernández-Hernández $\mathrm{F}$, Méndez-Tovar LJ, González-Monroy J, López-Martínez R. Fungal peritonitis in 15 patients on continuous ambulatory peritoneal dialysis (CAPD). Mycoses. 2003;46(9-10):425-9.
6. Das R, Vaux E, Barker L, Naik R. Fungal peritonitis complicating peritoneal dialysis: report of 18 cases and analysis of outcomes. Adv Perit Dial. 2006;22:55-9

7. Rosa NG, Silva S, Lopes JA, Branco P, de Almeida E, Ribeiro C, Abreu F, Barbas J and Prata MM. Fungal peritonitis in peritoneal dialysis patients: is previous antibiotic therapy an essential condition? Mycoses. 2006;50:79-81.

8. Bibashi E, Memmos D, Kokolina E, Tsakiris D, Sofianou D and Papadimitriou M. Fungal peritonitis complicating peritoneal dialysis during an 11-year period: report of 46 cases. CID. 2003;36:927-31.

9. Lo SH, Chan CK, Shum HP, Chow VC, Mo KL, Wong $\mathrm{KS}$. Risk factors for poor outcome of fungal peritonitis in Chinese patients on continuous ambulatory peritoneal dialysis. Perit Dial Int. 2003;23 Suppl 2:S123-6.

10. Wong P, Mak S, Lo K, Tong GMW and Wong AKM. A retrospective study of seven cases of Candida parapsilosis peritonitis in CAPD patient: the therapeutic implication. Perit Dial Int. 2000;20:76-9.

11. Santos M, Pabilonia and Danguilan R. Fungal peritonitis in patients on continuous ambulatory peritoneal dialysis. Phil J Internal Medicine. 1997;35:169-72.

12. Piraino B, Bailie GR, Bernardini J, Boeschoten E, Gupta A, Holmes C, Kuijper EJ, Li PK, Lye W, Mujais S, Paterson DL, Fontan MP, Ramos A, Schaefer F and Uttley L. Peritoneal dialysis-related infection recommendation: 2005 update. Perit Dial Int. 2005;25:107-31.

13. Elhassan EA, Kaballo B, Fedail H, Abdelraheem MB, Ali T, Medani S, Tammam L, Basheir I, Taha A, Mandour M, El Awad K, Abu-Aisha H. Peritoneal Dialysis in the Sudan. Perit Dial Int. 2007; 27:503-10.

14. Avramovi M, Radovanovi-Velikovi R, Djordjevi V, Miti B, Kosti S. Fungal peritonitis in contiuous ambulatory peritoneal dialysis. Medicine and Biology. 1997;4(1):62-5.

15. Abraham G, Thiagarajan T, Mathew M. Prevention of peritoneal dialysis related infections as a means to prevent dropout. Indian J Nephrol. 2005;15(2):S10-S13.

16. Keogh JAB, Carr ME, Murray F, McEvoy M, Grant $\mathrm{G}$ and Keane CT. Treatment of fungal peritonitis in CAPD patients using peritoneal lavage. Perit dial Int. 1985;5(1):67-9. 